\title{
Estudo dos modelos assistenciais praticados por operadoras de planos privados de saúde
}

I ${ }^{1}$ Rosiene Maria de Freitas, ${ }^{2}$ Mariângela Leal Cherchiglia, ${ }^{3}$ Francisco

Carlos Félix Lana, ${ }^{4}$ Deborah Carvalho Malta, ${ }^{5}$ Eli lola Gurgel Andrade I

Resumo: Este estudo objetivou identificar a adoção, pelas operadoras, de modelos assistenciais que busquem a integralidade do cuidado, a partir da indução pela Agência Nacional de Saúde Suplementar (ANS). O universo foi composto por operadoras de planos de saúde atuantes no estado de Minas Gerais, nas modalidades autogestão, filantropia, medicina de grupo e cooperativa médica. As empresas foram descritas a partir dos cadastros da ANS. Foi realizada entrevista telefônica assistida por computador ETAC - para obtenção de dados sobre o acesso dos beneficiários aos serviços, estruturação da rede e implantação de modelos segundo linhas maternoinfantil, adulto/idoso, cardiovascular e neoplasias. Foram constatadas 182 empresas em atividade no estado; 108 foram elegíveis para o estudo; 27,1\% das operadoras informaram ter implantado programas de cuidado na linha materno-infantil; 22,2\%, na linha de cuidado ao adulto/idoso e 9,2\% em neoplasias. Inadequadas estruturas internas e o pequeno porte da maioria das operadoras podem explicar, em parte, a dificuldade de implantação e modelos de atenção mais cuidadores. Ressalta-se a ampla margem de inovações ainda existente para a introdução dessas práticas por parte das operadoras.

> Palavras-chave: saúde suplementar; sistemas pré-pagos de saúde; regulação e fiscalização em saúde; seguro saúde.

\author{
1 Bióloga, mestre em Saúde \\ Pública pela Universidade \\ Federal de Minas Gerais, \\ técnica da Secretaria Municipal \\ de Saúde de Belo Horizonte. \\ Endereço eletrônico: \\ rosiene.freitas@hotmail.com \\ ${ }^{2}$ Médica, professora do \\ Departamento de Medicina \\ Preventiva e Social da Faculdade \\ de Medicina da UFMG, \\ doutora em Saúde Pública pela \\ Universidade de São Paulo. \\ Endereço eletrônico: \\ cherchml@medicina.ufmg.br \\ ${ }^{3}$ Enfermeiro, professor \\ do Departamento de \\ Enfermagem Materno-Infantil \\ e Saúde Pública da Escola de \\ Enfermagem da UFMG, doutor \\ em Enfermagem pela Escola de \\ Saúde Pública de Ribeirão Preto \\ - USP. Endereço eletrônico: \\ xicolana@enf.ufmg.br \\ ${ }^{4}$ Médica, professora \\ Departamento de Enfermagem \\ Materno-Infantil e Saúde \\ Pública da Escola de \\ Enfermagem da UFMG, \\ doutora em Saúde Coletiva \\ pela Universidade Estadual de \\ Campinas. Endereço eletrônico: \\ dcmalta@uol.com.br \\ ${ }^{5}$ Economista, professora do \\ Departamento de Medicina \\ Preventiva e Social da Faculdade \\ de Medicina da Universidade \\ Federal de Minas Gerais, \\ doutora em Demografia pela \\ UFMG. Endereço eletrônico: \\ iola@medicina.ufmg.br
} Aprovado em: 06/10/2011. 


\section{Introdução}

A saúde suplementar no Brasil cresceu nos anos 70 a partir da crise do modelo médico-previdenciário, bem como pelo forte incremento da modalidade convênioempresa, inaugurada em meados da década anterior. Nos anos 80, os baixos investimentos em saúde e, consequentemente, a queda na qualidade dos serviços prestados, favoreceram a progressiva migração dos setores médios da sociedade para planos e seguros privados de assistência à saúde. Atualmente, cerca de 51 milhóes de beneficiários possuem planos de saúde - em suas diversas modalidades -, o que corresponde a cerca de $20 \%$ da população brasileira (ANS, 2009).

Por mais de 30 anos, o setor permaneceu ausente de regulamentação específica. Com as leis 9.656/1998 e 9.961/2000, que definem regras para seu funcionamento e criam a Agência Nacional de Saúde Suplementar (ANS), estruturou-se o marco regulatório do setor. Originalmente, o processo regulatório da ANS estava centrado em três linhas de atuação: a regulação da saúde financeira das operadoras, a fiscalização dos contratos e sua relação de consumo e a fiscalização dos produtos, com destaque para cobertura e preço. No período inicial de atuação da ANS, portanto, a produção de saúde pelas operadoras ainda não havia adquirido a centralidade necessária para nortear o processo regulatório (MALTA et al., 2004).

A partir de 2004, constatado que o conjunto de recursos tecnológicos encontrava-se alocado em ações desarticuladas, pouco cuidadoras, médicocentradas e incorporando acriticamente novas tecnologias, a ANS estabeleceu como meta induzir a mudança na lógica assistencial da saúde suplementar e, por conseguinte, a responsabilização das operadoras para com a saúde de seus beneficiários. Adota-se como premissa para essa mudança que as operadoras de saúde devem cuidar da saúde dos beneficiários e ofertar opções de cuidado e ainda, conforme afirma Santos (2005), "que a saúde suplementar se volte para o atendimento das necessidades da população beneficiária, de forma integral, resolutiva e com a qualidade necessária". Para isso, a ANS passou a investir em um modelo de regulação que inclui a regulação assistencial (SANTOS, 2005).

$\mathrm{Na}$ consecução desse modelo, torna-se importante compreender a integralidade da assistência prestada aos beneficiários: uma das formas consiste em acompanhar o cuidado prestado para o restabelecimento de sua saúde. Partindo dessa compreensão, a ANS instituiu, em 2004, o Programa de Qualificação da Saúde Suplementar (PQSS). O programa pretendeu transformar operadoras de planos 
em gestoras de saúde e prestadores de serviços em produtores de cuidado de saúde. E, ainda, o PQSS buscou qualificar a ANS para corresponder à tarefa de regular o setor (ANS, 2009). O PQSS avalia as operadoras nas dimensões: qualidade da atenção à saúde; situação econômico-financeira; estrutura e operação; e satisfação dos beneficiários. Neste, a qualidade da atenção à saúde possui, inequivocamente, a maior potência indutora da mudança esperada.

O PQSS - enquanto mecanismo indutor estabelecido pela ANS para a mudança da lógica assistencial - é o ponto de partida para a análise proposta neste estudo, entendendo que o setor de saúde suplementar é um lugar de produção de saúde.

O objetivo do estudo é identificar a adoção, pelas operadoras, de modelos assistenciais que busquem a integralidade do cuidado.

\section{Metodologia}

No estudo foram analisadas operadoras de planos de saúde com sede no estado de Minas Gerais, nas modalidades: autogestão, medicina de grupo, cooperativa médica e filantropia. Não constam da análise as seguradoras, pelo fato de não haver nenhuma com sede em Minas Gerais. As cooperativas odontológicas e odontologias de grupo foram também excluídas da análise por não ser foco da investigação em relação ao cuidado prestado e à regulação da assistência nos temas adulto/idoso (cardiovasculares e neoplasias) e atenção materno-infantil. $\mathrm{O}$ estudo se apoiou em metodologias quantitativas e qualitativas (ANDRADE et al, 2009). Neste artigo serão descritos os métodos quantitativos adotados e os demais serão objeto de futuras publicações.

Inicialmente buscou-se caracterizar o universo das operadoras a partir de informações contidas nos cadastros da ANS, atualizados até março de 2007, acerca da modalidade e do número de beneficiários por operadora. De posse dessas classificações, foi realizada Entrevista Telefônica Assistida por Computador ETAC - no universo das operadoras de MG, objetivando a coleta de informações quanto aos modelos assistenciais implementados antes e depois do PQSS.

$\mathrm{O}$ método ETAC utiliza o survey telefônico, metodologia aplicada a estudos exploratórios caracterizada pela busca primária de informações via telefone, com o uso concomitante de computador. Para a execução da pesquisa, foram elaborados um questionário e, posteriormente, uma "máscara" em software especializado Microsoft Access $\AA$, abordando os seguintes aspectos: a) acesso 
dos beneficiários aos serviços prestados; b) estruturação da rede de assistência pela operadora; c) implantação de modelos assistenciais segundo algumas das linhas de cuidado preconizadas pelo PQSS: materno-infantil, adulto/idoso, cardiovascular e neoplasias; d) características das práticas implantadas quanto aos focos e processo de trabalho.

Adota-se o conceito de linha do cuidado, entendida aqui como o percurso do usuário na rede de assistência, que se estende conforme suas necessidades (Malta et al, 2004). A garantia do cuidado implica na responsabilização da operadora e do prestador pelo usuário, tornando-se a primeira gestora desse cuidado.

Para o desenvolvimento da ETAC, foi feita a comunicação oficial da pesquisa aos dirigentes das operadoras, com o objetivo de identificar o interlocutor e minimizar possíveis dificuldades em se obter dados a partir de uma entrevista telefônica. Após a comunicação a respeito da pesquisa, as operadoras foram entrevistadas, via telefone, com o preenchimento do questionário no computador. Os respondentes da entrevista telefônica foram o representante legal ou a pessoa delegada. As entrevistas foram realizadas nos meses de fevereiro e março de 2007, por empresa especializada na execução desta atividade, com capacitação prévia por parte da coordenação da pesquisa.

Para a avaliação das práticas assistenciais adotadas e da implantação de linhas de cuidado, foram identificados alguns eventos, definidos nesta pesquisa como marcadores para verificação das ações contempladas pelos programas relatados pelas operadoras. A definição desses eventos foi orientada pelas áreas de abordagem do estudo, bem como por indicadores e eventos sentinela definidos no PQSS. As operadoras foram questionadas primeiramente sobre a implantação (ou não) de programas nessas áreas. Àquelas que responderam positivamente, para cada área, foram dirigidas questôes específicas sobre os programas.

$\mathrm{Na}$ área materno-infantil, o questionário investigou se o programa adotado contempla: a) estratégias de captação precoce das gestantes; b) definição do número de consultas de pré-natal; c) definição do número de exames de ultrassonografia; d) definição e acompanhamento do rol de exames de patologia clínica e sua periodicidade; e) realização de grupos operativos; f) estratégias para identificação, captação e acompanhamento em protocolo específico para gestantes de alto risco; g) e outras práticas, não relacionadas neste rol. Também foram investigados o acesso aos exames pré-natal, a existência de (e quais) eventos- 
sentinela adotados para avaliação da qualidade do pré-natal, e as estratégias para acompanhamento e adequação do número de partos cesáreos às recomendações da Organização Mundial de Saúde - OMS.

Para as linhas de cuidado cardiovascular e neoplasias, o questionário abordou, dentre outros, o acompanhamento de indicadores pelos programas implantados: a) internações por diabetes mellitus, amputação de membros inferiores por diabetes mellitus, doenças cerebrovasculares, infarto agudo do miocárdio, neoplasia maligna de cólon e reto, neoplasia maligna de mama feminina e neoplasia maligna de próstata; b) mortalidade por doenças do aparelho circulatório e por doenças cerebrovasculares.

Foram desenvolvidas questôes relativas ao acesso dos beneficiários à rede de serviços de assistência e à estruturação desta rede, com o objetivo de qualificar as respostas das operadoras quanto às linhas de cuidado implantadas. Sobre a regulação assistencial praticada, a ETAC abordou questōes relativas a acesso, auditoria médica, segunda opinião médica e autorização prévia pelas operadoras, visando identificar potenciais mecanismos regulatórios e barreiras assistenciais resultantes dessas práticas. Ainda, foram aplicadas questôes sobre formas de comunicação, direcionamento de rede e critérios de seleção dos prestadores.

Os resultados encontrados foram tabulados e descritos em números absolutos e proporções, apresentando o perfil das operadoras com sede em MG quanto ao porte, aos programas de assistência, às linhas de cuidado implantadas nas áreas selecionadas, e aos mecanismos regulatórios utilizados.

A investigação foi realizada dentro dos preceitos éticos estabelecidos pela Resolução 196/06 do Conselho Nacional de Saúde e aprovada, conforme o Parecer no 387/06 de 19 de dezembro de 2006, do Comitê de Ética da UFMG. O projeto foi desenvolvido pelo Grupo de Pesquisa em Economia da Saúde da UFMG, com apoio financeiro da Cooperação Técnica OPAS/Rede de Centros Colaboradores da ANS 2006/2008.

\section{Resultados}

\section{Perfil das operadoras}

O estado de $M G$ possui 13 regiōes administrativas. O maior número de operadoras - 39,5\% das empresas - encontra-se na macrorregião Centro, que concentra $31,6 \%$ da população total e, consequentemente, a maior oferta e demanda de 
serviços. A região de menor concentração populacional - Jequitinhonha - com $1,4 \%$ da população total do estado, possui apenas uma operadora, na modalidade Filantropia. Por se tratar de região pouco desenvolvida do ponto de vista sócioeconômico, infere-se a razão da não instalação de outras modalidades.

Em 2007, apenas 16,7\% da população do estado encontrava-se coberta por planos privados de saúde, sendo que $55,4 \%$ dos beneficiários concentravam-se na macrorregião Centro e $0,01 \%$ na macrorregião Jequitinhonha. A pesquisa nos bancos de dados da ANS, em março de 2007, informou 230 operadoras de planos de saúde atuando no estado de MG.

A maior parte das operadoras $(54,8 \%)$ possui até 10.000 beneficiários, abrangendo $13,7 \%$ da população de beneficiários do estado; $11,3 \%$ das empresas possuem entre 20.001 e 50.000 beneficiários; $4 \%$ entre 50.001 e 100.000 beneficiários. Esses dois últimos intervalos abrangem $47,4 \%$ da população. Apenas uma operadora, na modalidade cooperativa médica, possui mais de 500.001 beneficiários, concentrando $17,7 \%$ da população coberta por planos de saúde no estado.

Na ETAC, constatou-se que 48 empresas (20,8\%) haviam encerrado suas atividades, resultando em um universo de 182 empresas no estado (tabela 1). Destas, $42(23,1 \%)$ recusaram-se a responder à pesquisa e duas $(1,1 \%)$ não finalizaram o questionário. Na ETAC, portanto, 138 empresas $-76,0 \%$ das operadoras de MG - tiveram entrevistas concluídas.

A análise apresentada nesse estudo, pelo seu objeto, excluiu as 14 operadoras de odontologia de grupo e as 16 cooperativas odontológicas. O universo analisado abrangeu 108 empresas nas modalidades autogestão, cooperativa médica, filantropia e medicina de grupo (tabela 1). Estas representam 59,3\% do total de operadoras atuando no estado, e cobrem $62,6 \%$ do total de beneficiários.

\section{Mecanismos de regulação; informação e comunicação}

Analisadas quanto aos mecanismos de acesso dos beneficiários aos serviços, 93 operadoras $(86,1 \%)$ declararam adotar normas para a utilização dos serviços assistenciais (tabela 2). Considerou-se nessa questão a ocorrência de resposta positiva a mais de um dos critérios.

Os mecanismos mais utilizados são a autorização prévia $(78,7 \%)$ e a auditoria médica $(73,1 \%)$. A coparticipação, entendida como estratégia de controle do 
consumo de procedimentos, na qual o beneficiário arca com parte do custo e, em algumas situações, com o pagamento de franquia, foi relatada por $26,9 \%$ das empresas (29). Destacou-se também, a utilização da segunda opinião médica encaminhamento do beneficiário a outro especialista para avaliação da solicitação - relatada por 14,8\% das operadoras (16). Esse mecanismo é utilizado com mais frequência para a autorização de procedimentos de alta complexidade, sendo que a análise da solicitação pode ou não estar baseada em protocolos clínicos.

As operadoras foram também questionadas a respeito do direcionamento dos beneficiários a determinados prestadores, com o objetivo de avaliar se este atende a uma matriz de desempenho do prestador (principalmente o médico), que mede o custo e/ou volume de procedimentos e busca a racionalização do uso do sistema, ou se atende a critérios que incluem a qualidade da assistência prestada, implantação de linhas de cuidados, adoção de protocolos clínicos, dentre outros.

Dentre as 108 operadoras pesquisadas, $31(28,7 \%)$ responderam que direcionam os beneficiários em sua rede assistencial. Destas, 61,3\% declararam que o fazem em atenção à disponibilidade de prestadores em sua área de abrangência e 41,9\% devido a encaminhamentos de outro profissional. Apenas 9,7\% o fazem pela inserção dos beneficiários em alguma linha de cuidado e 3,2\% por existência de protocolo clínico definido. Em situações menos frequentes, foi citado que o direcionamento é feito a pedido dos beneficiários, e em casos de urgência (dados não mostrados).

A ETAC também abordou a existência e a forma de comunicação da operadora com os beneficiários, entendendo que os mecanismos informacionais adotados podem ser utilizados para ações de promoção e prevenção, no atendimento ou acolhimento às necessidades dos beneficiários, ou no controle do acesso aos serviços.

Do total de 108 operadoras analisadas, 99 (91,6\%) alegaram possuir mecanismos institucionalizados de informação/comunicação com seus beneficiários (tabela 3), com maior frequência para a utilização de catálogo de prestadores $(71,3 \%)$, manuais e normas de utilização do plano, e informaçôes veiculados através de sítios na internet $(64,8 \%)$.

A utilização de call center foi identificada em 29,6\% dessas operadoras, que foram questionadas sobre as atividades executadas por esse serviço. A maior parte das empresas utiliza o call center para fornecer informações gerais aos beneficiários 
$(78,1 \%)$. Também com grande incidência constataram-se a marcação e agendamento de procedimentos $(46,9 \%)$ e as autorizações prévias $(59,4 \%)$. Apenas $18,9 \%$ das operadoras informaram utilizá-lo para o monitoramento de casos. Vale observar que as empresas puderam responder positivamente a mais de um item nessa questão (dados não mostrados).

\section{Critérios de seleção de prestadores}

O estudo procurou relacionar as formas de seleção e vinculação de prestadores individuais e empresariais com a construção da rede assistencial, de forma a prestar uma assistência não fragmentada e não pautada no consumo de procedimentos. A tabela 4 apresenta os critérios utilizados pelas operadoras para a seleção de prestadores, bem como os vínculos estabelecidos entre eles.

Para todas as modalidades $(\mathrm{N}=108)$, os critérios de seleção mais frequentes foram a reputação dos profissionais no mercado $(61,1 \%)$ e o grau de especialização destes $(64,8 \%)$. A seleção de prestadores individuais a partir do perfil epidemiológico dos beneficiários foi um critério informado por $27,8 \%$ das operadoras, e a indicação externa (de outros profissionais, empresas, outros), por $19,4 \%$. Entre as modalidades, destacando-se as empresas de medicina de grupo, foi percebida maior diferença na utilização do grau de especialização dos profissionais enquanto critério para seleção de prestadores.

A vinculação dos prestadores individuais - considerada importante neste estudo, pelas possíveis e diversas interações que determinam com as operadoras -, na maior parte das modalidades, se dá por contrato de prestação de serviços. A exceção ocorre nas cooperativas médicas, pela própria natureza dessas empresas (92,6\% são cooperados).

Para a seleção de prestadores empresariais, os critérios identificados com maior frequência foram a reputação das empresas $(61,1 \%)$ e a disponibilidade do serviço no mercado $(52,8 \%)$. A seleção de prestadores a partir da demanda (dos beneficiários, dos próprios prestadores e das indústrias) por incorporação de novas tecnologias, do perfil epidemiológico da carteira de beneficiários, ou a partir da indução dada pelo PQSS, foi informada por 31,5\% nos dois primeiros critérios e 33,3\% no último. A maior parte dos prestadores empresariais é vinculada às operadoras por contrato $(92,6 \%)$, e a prática de livre escolha e referenciamento correspondem a apenas $2,8 \%$. 


\section{Linhas de cuidado: implantação e desenvolvimento de práticas}

Quanto à linha de cuidado materno-infantil, apenas 27,7\% das operadoras citaram ter implantado programas. Estes incluíram com maior frequência em suas práticas: a captação precoce de gestantes $(8,3 \%)$; a definição do rol de exames e sua periodicidade (6,4\%); a definição do número de consultas prénatal (6,4\%); e a identificação e o acompanhamento, em protocolo específico, das gestantes de alto risco $(6,4 \%)$.

Quanto aos mecanismos de acesso aos exames pré-natal, foi informado que estes se dão diretamente a partir da solicitação médica, para $88 \%$ das operadoras; de autorizaçôes prévias (35,2\%), ou, 11\% em se observando os protocolos estabelecidos para a linha de cuidado (dados não mostrados).

Com relação ao número de partos cesáreos ocorridos na rede prestadora, 24 operadoras $(22,2 \%)$ declararam estar de acordo com a meta preconizada pela OMS. Daquelas que declararam não estarem adequadas à meta, 26 (44,8\%) informaram utilizar mecanismos para a adequação. Estes se constituem, em sua maioria, por campanhas de conscientização junto aos beneficiários e médicos, através de palestras, folhetos informativos, seminários, assembleias e cursos. Houve resposta, por parte de uma operadora, de pagamento diferenciado aos médicos como incentivo à realização do parto normal.

Foi informada por 24 operadoras $(22,2 \%)$ a adoção da saúde do idoso/adulto como uma das áreas de atuação, incorporando cuidados a beneficiários diabéticos e hipertensos e a doenças cardiovasculares. Dez operadoras $(9,25 \%)$ informaram ter implantado linhas de cuidado no tema neoplasias. A tabela 5 apresenta os eventos e indicadores informados pelas operadoras para o acompanhamento dos beneficiários nos programas implantados, por ocorrência e modalidade. Ressaltase que a operadora podia informar sobre o acompanhamento de um ou mais indicadores/eventos.

Nos programas de prevenção do câncer de mama feminino foram citadas como estratégias para mobilização: a realização de palestras sobre o tema para prestadores e beneficiárias, campanhas publicitárias e distribuição de folhetos informativos. Uma operadora citou o desenvolvimento de programa de acompanhamento de mulheres com histórico familiar de câncer de mama. Quanto às estratégias para mobilizar prestadores e beneficiários na faixa etária de 25 a 59 anos para a realização anual de procedimentos preventivos do câncer 
de próstata, foram citadas campanhas publicitárias, distribuição de cartazes e informativos, acompanhamento dos beneficiários na faixa etária de risco e com histórico familiar de câncer de próstata, e o incentivo através de visita domiciliar.

\section{Discussão}

A atual discussão do modelo assistencial praticado pelas operadoras de planos de saúde parte do pressuposto de que é possível que as empresas organizem práticas cuidadoras, que garantam a integralidade da atenção e melhorem a resposta dada ao beneficiário. A qualidade da atenção dispensada depende do cuidador, mas também do acesso aos serviços e da qualidade da rede.

A pesquisa realizada nas operadoras com sede em Minas Gerais mapeou as linhas de cuidado selecionadas visando, indiretamente, verificar os cuidados dispensados aos beneficiários. Este trabalho objetivou identificar também medidas regulatórias, em especial a regulação assistencial, buscando identificar práticas que possam cercear o cuidado dispensado.

Para a análise, utilizaram-se como marco referencial as medidas regulatórias adotadas pela ANS nos últimos anos, como o PQSS, que visaram ampliar a capacidade regulatória do Estado, especialmente a regulação do cuidado à saúde através da compreensão e da intervenção sobre os processos assistenciais. Ao entender como as operadoras atuam nos mecanismos assistenciais, a ANS e o Estado podem intervir buscando a qualidade e a integralidade da assistência (ANS, 2008).

A regulação introduzida com a Lei 9.656/1998, e a criação da ANS em 2000 estabelecem novas possibilidades para a relação no setor suplementar de saúde, provocando uma revisão dos processos no sentido de ampliação das coberturas assistenciais, com controle de custos e monitoramento da qualidade. Pode-se hoje afirmar que o setor está saindo de uma lógica de regulação econômico-financeira para uma realidade de regulação pela qualidade da atenção (MALTA et al., 2004).

Por outro lado, no setor de saúde suplementar, as relações entre beneficiários, operadoras e prestadoras são consideradas tipicamente de mercado. Diferentemente do sistema público, no qual se encontram cidadãos com direitos constitucionais assegurados, no setor suplementar, tradicionalmente, a assistência esteve vinculada a um conjunto de serviços relacionados em contrato. Com certeza, essa perspectiva tem comprometido, ao longo dos anos, a adoção de modelos integrais de atenção. 
O estudo atingiu uma amostra representativa das empresas no Estado: das operadoras consideradas elegíveis, 23\% se recusaram a responder, não havendo, contudo, perda diferencial. Todas as modalidades e faixas de quantitativos de beneficiários foram inseridas.

A realização da pesquisa constatou que uma alta frequência de empresas $(20,8 \%)$ havia encerrado suas atividades e ainda permanecia nos cadastros da ANS, o que pode ser explicado pela existência de pendências para o cancelamento do registro junto à agência.

Dentre os resultados do estudo, destacamos a concentração das operadoras na região mais rica do estado, e a grande exclusão de coberturas no norte e em Jequitinhonha, o que é coerente com os resultados da PNAD, que mostram maior cobertura de planos entre população de maior renda e escolaridade (IBGE, 2005). $\mathrm{O}$ estudo mostra ainda a grande presença das empresas de medicina de grupo no mercado mineiro, seguidas das cooperativas médicas e das empresas de autogestão. As seguradoras não têm sede no estado, embora tenham segurados. Esse fato reforça muito a atuação do mercado local e favorece a ampla predominância de uma cooperativa médica em MG, detendo mais de 17\% dos beneficiários. Esse panorama é bem distinto do cenário nacional (SANTOS et al, 2008).

Quanto à modalidade de vinculação com prestadores, predomina a contratação de serviços. A exceção fica por conta das cooperativas que tem no médico cooperado a sua forma preponderante de vinculação.

Estudo que trabalhou os mecanismos de microrregulação das operadoras em relação aos hospitais apontou que 91,2\% destes prestadores, no país, são vinculados por meio de contratos formais. Os autores assinalam que esses contratos raramente incorporam aspectos relativos à qualidade da assistência a ser prestada, limitando-se à definição de valores, prazos e procedimentos para pagamento (UGÁ et al, 2009). Entretanto, como afirmam Malta e Jorge (2008), com base em estudo realizado em uma operadora de MG, observa-se a implantação de um novo modelo assistencial apoiado na busca de reorganização da rede prestadora, a partir de serviços próprios, com porta de entrada no sentido de aumentar a capacidade de regulação da operadora e possibilitar a garantia da qualidade dos serviços. As autoras destacam ainda, na relação das operadoras com os prestadores empresariais hospitalares, a tendência do mercado em contratar pacotes de serviços previamente acordados (para cirurgias, por exemplo), definindo preços 
1572 de serviços médicos, de enfermaria e auxiliares, materiais e hotelaria, a partir de séries históricas e considerando determinado padrão tecnológico.

Quanto aos mecanismos de regulação adotados pelas operadoras, já bastante descritos pela literatura (MALTA et al, 2005; CECÍLIO et al, 2005; RIBEIRO et al, 2008), predominam a autorização prévia, a perícia médica (ou auditoria) e, em menor proporção (30\%), as coparticipações. Ribeiro et al. (2008), em estudo a partir de amostra intencional em 23 operadoras do país, relatam que a auditoria é o principal procedimento adotado pelas empresas para o controle de custos e qualidade. Mostram também que são pouco informadas estratégias mais complexas - como o uso de protocolos clínicos - de adequação do controle de custos ou da gestão da qualidade.

Para o direcionamento dos beneficiários na rede, as operadoras se referenciam na disponibilidade do profissional na região (62\%) e nos encaminhamentos realizados pelos profissionais (42\%), o que reforça a importância do médico como indutor e responsável pela linha de cuidado. É importante destacar que a visão dos beneficiários não foi captada, podendo esta ser distinta daquela das operadoras. Portela et al (2008), em estudo realizado com 90 operadoras no país a respeito do uso de diretrizes clínicas voltadas para a melhoria da qualidade assistencial, relatam que 32,3\% declaram sua condução e uso e que, entre estas, $51 \%$ direcionam os beneficiários aos prestadores que aderem às diretrizes.

Os mecanismos de comunicação com os beneficiários também já estão bastante descritos na literatura. Nesse estudo, manuais, catálogos, e call centers foram declarados por apenas $32 \%$ das empresas quando, no mercado, este último tem sido o grande mecanismo adotado pelas operadoras de maior porte (MALTA et al, 2005). O call center tem sido avaliado como uma alternativa de porta de entrada do beneficiário - seja em serviços de urgência, consultórios ou clínicas especializadas vinculados às operadoras - de forma articulada para a produção de um cuidado não fragmentado, e também como um instrumento para a captação, monitoramento e acompanhamento de usuários com algum risco diferenciado avaliação do uso de vacinas, acompanhamento de idosos, hipertensos, diabéticos, etc. A baixa frequência de utilização constatada neste estudo pode ter como uma justificativa o pequeno porte da maioria das operadoras que atuam no mercado mineiro: $54,8 \%$ possuem até 10.000 beneficiários. 
Os mecanismos constatados de seleção dos prestadores também foram os esperados: especialização e reputação do profissional ou serviço, demanda pelo serviço (MALTA et al., 2005). Coincidente com esse estudo Ribeiro et al. (2008) destacam em sua pesquisa a qualificação, titulação e competência do profissional como critérios para seleção de prestadores em $86,9 \%$ das unidades pesquisadas.

As linhas de cuidado materno-infantil são pouco informadas: apenas 30 operadoras declaram tê-las implantado. No caso especifico do monitoramento dos partos cesáreos, as respostas mostram que as operadoras não têm uma grande atuação visando a essa redução.

De acordo com informações contidas nas fichas técnicas dos indicadores do PQSS, a proporção de partos cesáreos ocorridos no setor de saúde suplementar foi de 79,2\% em 2004, 77,5\% em 2005 e 80,7\% em 2006. No Sistema Único de Saúde - SUS - e no Brasil, respectivamente, a proporção foi de 27,5 e 41,8\%, em 2004, e 28,6 e 43,3\% em 2005. Em 2006, no SUS, essa proporção foi de $30,1 \%$. Esses dados são totalmente discrepantes em relação à recomendação da OMS - 25\% de partos cesáreos relativamente ao total de partos -, bem como em relação aos resultados encontrados em outros países: Holanda (14\%), EUA (31\%), México (34\%) e Chile (40\%) (TORRES, 2009).

As ações esperadas para a redução desses números na saúde suplementar incluem o acompanhamento do pré-natal, de forma a reduzir as indicações cirúrgicas e com o objetivo de que estas ocorram somente com indicações precisas; a disseminação de informações sobre as vantagens do parto normal e os riscos do parto cirúrgico; o estabelecimento de sistemas de acompanhamento e supervisão das indicações; a pactuação e a sensibilização de prestadores quanto à qualificação da assistência materno-neonatal; a disseminação de informaçoos; e a divulgação de indicadores junto aos prestadores.

Da mesma forma, o monitoramento das linhas de cuidado dos adultos e idosos (cardiovascular e neoplasias) é muito pouco relatado, e as estratégias descritas ainda apontam para o estágio de detecção e diagnóstico do problema. No acompanhamento dos indicadores desses temas esperam-se: a captação precoce de casos; o acompanhamento, objetivando o controle das doenças e aumento da sobrevida; a sensibilização e pactuação com os prestadores sobre a importância da prevenção e da qualidade da assistência; a divulgação das metas e 
dos indicadores junto aos prestadores; e a constituição de sistemas de informação que definam o perfil epidemiológico dos beneficiários (ANS, 2009).

Sem esgotar os diversos desafios colocados para o setor de saúde suplementar - do ponto de vista dos beneficiários, com o direito à qualidade da assistência; dos prestadores, com o desafio de serem engajados no processo de produção integral da saúde; das operadoras, que necessitam articular a regulação sobre os prestadores e a garantia da qualidade aos beneficiários, sem perder de vista os custos da atenção; e da ANS, para cumprir seu papel regulatório -, este estudo identificou iniciativas positivas para a produção de uma assistência mais integral e cuidadora, estas ainda incipientes.

São diversos os desafios colocados para o setor de saúde suplementar: do ponto de vista dos beneficiários, com o direito à qualidade da assistência; dos prestadores, com o desafio de serem engajados no processo de produção integral da saúde; das operadoras, que necessitam articular a regulação sobre os prestadores e a garantia da qualidade aos beneficiários, sem perder de vista os custos da atenção; e da ANS, para cumprir seu papel regulatório. Sem pretender ter esgotado esta discussão, o presente estudo identificou iniciativas positivas para a produção de uma assistência mais integral e cuidadora, ainda que incipientes.

Considerando os resultados apresentados e as experiências da literatura aqui citada, as inadequadas estruturas internas e o pequeno porte da maioria das operadoras atuantes no estado podem explicar, em parte, a dificuldade de aplicação das mudanças. Uma hipótese, merecedora de estudos específicos, é a de que operadoras de maior porte têm implantado com maior ênfase modelos mais cuidadores, fato que provavelmente também se associa a um maior conjunto de alternativas para o uso eficiente dos recursos financeiros e tecnológicos disponíveis. Entretanto, há que se ressaltar a ampla margem para inovaçôes ainda existente, no sentido da introdução de práticas efetivamente cuidadoras, em contraposição à simples mediação, por parte das operadoras, das relações entre os prestadores e beneficiários, com o objetivo de controle de custos ou de compartilhamento de riscos. 


\section{Referências}

ANDRADE, E.I.G. et al. In: PEREIRA, R.C., SILVESTRE, R.M. (Orgs.). Regulação $e$ modelos assistenciais em saúde suplementar: produção científica da Rede de Centros Colaboradores da ANS - 2006/20098. Brasília: Organização Pan-Americana de Saúde, 2009. p. 87-118.

AGÊNCIA NACIONAL DE SAÚDE SUPLEMENTAR. Programa de qualificação da Saúde Suplementar. Rio de Janeiro Fevereiro: ANS, 2009. Disponível em: <http://www. ans.gov.br/portal/site/_qualificacao/pdf/texto_base.pdf>. Acesso em: 21 out. 2009.

. Caderno de Informaçôes. Rio de Janeiro, 2009. Disponível em: <http://www.ans. gov.br/portal/site/_ >. Acesso em: 05 mar. 2009.

- Panorama das Açôes de Promoção da saúde e prevenção de riscos e doenças na Saúde Suplementar. Rio de Janeiro: ANS, 2008, 88 p.

CECÍLIO, L.C. et al. A saúde suplementar na perpectiva da microregulação. In: MALTA, D.C. et al. (Orgs.). Duas faces da moeda: microrregulação e modelos assistenciais na Saúde Suplementar. 1 ed. Brasília: Ministério da Saúde, 2005.

INSTITUTO BRASILEIRO DE GEOGRAFIA E ESTATÍSTICA. Pesquisa Nacional por Amostra de Domicílios. Acesso e Utilização de Serviços de Saúde 2003. Brasília: Ministério do Planejamento, 2005.

MALTA, D.C. et al. Perspectivas da regulação na saúde suplementar diante dos modelos assistenciais. Ciência e Saúde Coletiva, Rio de Janeiro, v. 9, n. 2, p. 433-444, 2004.

MALTA, D.C. et al. Os modelos assistenciais praticados nas operadoras investigadas. In: MALTA, D.C. et al. (Orgs.). Duas faces da moeda: microrregulação e modelos assistenciais na Saúde Suplementar. 1 ed. Brasília: Ministério da Saúde, 2005. p. 161-199.

MALTA, D.C.; JORGE, A.O. Modelos assistenciais na saúde suplementar: o caso de uma operadora de autogestão. Ciência e Saúde Coletiva [periódico na Internet], v. 13, n. 5, p. 1535-1542, 2008. Disponível em: <http://www.scielo.br/scielo.php?script=sci_ arttext\&pid=S1413-81232008000500018\&lng=pt > Acesso em: 01 mar 2009.

PORTELA, M.C. et al. Diretrizes clínicas e outras práticas voltadas para a melhoria da qualidade assistencial em operadoras de planos de saúde sob a perspectiva de seus dirigentes, no Brasil. Cadernos de Saúde Pública, v. 24, n. 2, p. 253-266, 2008.

RIBEIRO, J.M. et al. Procedimentos e percepções de profissionais e grupos atuantes em mercados de planos de saúde no Brasil. Ciênc. saúde coletiva, v. 13, n. 5, p. 1477-1487, 
2008. Disponível em: <http://www.scielo.br/scielo.php?script=sci_arttext\&pid=S141381232008000500013\&lng=pt > Acesso em: 01 mar 2009.

SANTOS, F.P. Apresentação. In: MALTA, D.C. et al. (Orgs.). Duas faces da moeda: microrregulação e modelos assistenciais na Saúde Suplementar. 1 ed. Brasília: Ministério da Saúde, 2005.

SANTOS, F.P.; MALTA, D.C.; MERHY, E.E. A regulação na saúde suplementar: uma análise dos principais resultados alcançados. Ciência e Saúde Coletiva [periódico na Internet], v. 13, n. 5, p. 1463-1475, 2008. Disponível em: <http://www.scielo.br/scielo.php?script=sci_ arttext\&pid=S1413-81232008000500012\&lng=pt.> Acesso em: 01 mar 2009.

TORRES, J.A.A redução do parto cesáreo: o papel do SUS e da saúde suplementar. Apresentação em PowerPoint. Disponível em: <http://anstabnet.ans.gov.br/data/files/8A958865266CA FE201268A545DA371C5/XXIVConasems_A\%20redu\%C3\%A7\%C3\%A3o\%20do\%20 parto\%20ces\%C3\%A1reo_JacquelineTorres_09abril.pdf > Acesso em: 01 mar 2009.

UGÁ, M.A.D. et al. Mecanismos de microrregulação aplicados por operadoras de planos de saúde sobre hospitais privados. Revista de Saúde Pública, v. 53, n. 5, p. 832-838, 2009. 
Study of care models practiced by private operators of health plans

This study aimed to identify the adoption by private health insurance companies, from the induction by the Agência Nacional de Saúde Suplementar (ANS) of models that foments integrality. The universe were companies in Minas Gerais, in the modalities self-management, philanthropy, group medicine and medical cooperative. The companies were described from ANS official registers. Also, was made a computer-assisted telephone interview - ETAC- which approached: the beneficiaries' access to services, the structuring of the network, and the introducion of care models on maternal and child health, adult/elderly, cardiovascular and cancer. There were found 182 companies in Minas Gerais; 108 were elegible; $27,1 \%$ reported the deployment of care models on maternal and child health; $22,2 \%$ on adult/elderly health and $9,25 \%$ on cancer. Inadequate internal structures and the small size of most companies may somehow explain the difficulty of implementing models of care that foments integrality. We highlight the wide scope for innovations that still exists for the introduction of these practices by the companies.

> Key words: supplemental health; health maintenance organizations; health regulation and surveillance; health insurance. 